\title{
Risk Factors of Hyperbilirubinemia - A Case-Control Study in a Tertiary Level Hospital in Rural Central India
}

\author{
Sinduja Selvam ${ }^{1}$, Amar Taksande ${ }^{2}$ \\ ${ }^{1,2}$ Department of Paediatrics, Jawaharlal Nehru Medical College, Sawangi (Meghe), Wardha, Maharashtra, India.
}

\section{ABSTRACT}

\section{BACKGROUND}

Hyperbilirubinemia is the most common cause of hospital readmission in neonates affecting about $60 \%$ of term and $85 \%$ of preterm neonates. Often, it is a benign condition but may result in neurological sequelae like bilirubin induced encephalopathy and kernicterus spectrum of disorders. We wanted to evaluate the foetal and maternal risk factors of hyperbilirubinemia and also identify the modifiable risk factors of it in neonates.

\section{METHODS}

An observational case - control study was carried out from July 2018 to July 2020. Neonates with hyperbilirubinemia levels in the range of phototherapy as described by the age and gestation by the American Academy of Paediatrics were taken as cases and neonates without hyperbilirubinemia were taken as controls. Detailed demographic-, prenatal-, perinatal-, family-history and physical-examination was undertaken for all the neonates included in the study and various risk factors were assessed such as the presence of maternal illness, intrauterine growth retardation (IUGR), premature rupture of membranes (PROM), prematurity, ABO and Rh incompatibility, previous history of phototherapy in siblings, breast feeding problems and birth asphyxia.

\section{RESULTS}

Multivariate logistic regression studies of data collected has shown a significant association between IUGR ( $P$ value 0.01), prematurity ( $P$ value 0.002), ABO incompatibility ( $P$ value 0.009), breast feeding problems (P value 0.001), birth asphyxia ( $P$ value 0.05 ) and presence of PROM (P value 0.05) with neonatal hyperbilirubinemia.

\section{CONCLUSIONS}

Early identification of neonatal hyperbilirubinemia and prompt intervention reduces the morbidity and mortality associated with this common condition.

\section{KEY WORDS}

Jaundice of Neonate, Neonatal Jaundice, Icterus Neonatorum

\author{
Corresponding Author: \\ Dr. Sinduja Selvam, \\ 1-D Jayaprakash Street, \\ Kottur - 642114, Coimbatore, \\ Tamil Nadu, India. \\ E-mail: sinduja.th@gmail.com
}

DOI: $10.14260 / j e m d s / 2021 / 393$

How to Cite This Article:

Selvam S, Taksande A. Risk factors of hyperbilirubinemia - a case-control study in a tertiary level hospital in rural Central India. $J$ Evolution Med Dent Sci 2021;10(25):1904-1909, DOI: 10.14260/jemds/2021/393

Submission 13-02-2021,

Peer Review 21-04-2021,

Acceptance 28-04-2021,

Published 21-06-2021.

Copyright (c) 2021 JEMDS. This is an open access article distributed under Creative Commons Attribution License [Attribution 4.0 International (CC BY 4.0)] 


\section{BACKGROUND}

Neonatal hyperbilirubinemia is the most common cause of hospital readmission among neonates. It affects about $60 \%$ of term and about $80 \%$ of preterm neonates. ${ }^{1}$ Hyperbilirubinemia or increased serum bilirubin levels manifest as jaundice, the yellowish discoloration of the skin, sclera and mucous membranes.

Often, it is a benign condition that resolves without any sequelae but in some cases, it may have significant mortality and morbidity due to the neurological sequelae like bilirubin induced encephalopathy and kernicterus spectrum of disorders. Neonates are more at risk for developing these sequelae due to the immature blood - brain barrier (BBB), in the early days of life.

Therefore, prompt recognition and monitoring of the neonates at risk for developing significant hyperbilirubinemia is important for early intervention and prevention of complications associated with neonatal hyperbilirubinemia.

Various factors have been associated with the presence of neonatal hyperbilirubinemia. These may be maternal factors like anaemia, hypothyroidism, TORCH (toxoplasmosis, other agents, rubella, cytomegalovirus, herpes simplex) infections, diabetes mellitus, hypertension, bad obstetric history, ABO and $\mathrm{Rh}$ incompatibility, breastfeeding problems, foetal factors like IUGR, oligohydramnios or polyhydramnios, neonatal factors like prematurity, birth weight, sepsis, urinary tract infections (UTI), presence of cephalohaematoma, familial factors like presence of jaundice in the family (haemolytic diseases, Dublin Johnson syndrome, Rotors syndrome) or environmental and social factors like time to initiation of breastfeeding, seasonal variation, etc. ${ }^{1-4}$

This study was conducted to determine the various risk factors both maternal and foetal, associated with neonatal hyperbilirubinemia and identify the modifiable risk factors that were predominant in the population included in this study, as there was a paucity of studies to define the prevalent causes of hyperbilirubinemia found in the population of rural central India.

\section{METHODS}

The approval (DU) / IEC / 2018 - 19 / 7475) of the Institutional Ethical Committee of the DMIMS University was taken. An observational case-control study was conducted in the neonatology department of a tertiary level rural hospital, from July 2018 to July 2020. A sample of 110 cases and 110 controls were taken, after calculation by two sided confidence levels $(1$ $-\alpha=95$ ).

\section{Inclusion Criteria}

Neonates with hyperbilirubinemia requiring phototherapy were included in the study as cases. The neonates whose serum bilirubin levels were in the range of phototherapy as per Bhutani Nomogram Charts ${ }^{4}$ for $>35$ weeks of gestation or National Institute for Health and Clinical Excellence (NICE) Guidelines $^{5}$ for neonates below 35 weeks of gestation were taken as cases. Neonates who did not have transcutaneous bilirubin $(\mathrm{TcB})$ in the range of phototherapy were taken as controls in a 1:1 age and sex matched ratio.

\section{Exclusion Criteria}

Neonates with congenital malformations, babies of parents not willing to participate in the study and neonates with incomplete information about pregnancy and delivery were not included.

All neonates delivered in our hospital were monitored twice daily through physical assessment and with transcutaneous bilirubinometer for the presence of hyperbilirubinemia.

A detailed information sheet was given to the parents of all neonates included in the study, in which the methodology of the study was explained. All neonates enrolled in the study were subjected to a physical examination.

The demographic data, prenatal, perinatal, and family history were collected. The presence of various risk factors was assessed. The maternal records were assessed for details of maternal illness, antenatal scans and details of labour or delivery. Breastfeeding was encouraged in all neonates as per the hospital norms and adequacy of feeding and problems of breastfeeding were assessed routinely by staff and residents. Mothers with inadequate secretions were advised to supplement feeds with donor milk from in - facility human milk bank.

Details of birth events were obtained from the neonates' case records. Laboratory investigations like complete blood count (CBC) with peripheral smear, septic screen, serum bilirubin levels, blood grouping, thyroid levels, glucose - 6 phosphate dehydrogenase (G6PD) levels were done in all cases included in the study.

As thyroid screening was not routinely done in all the neonates, the thyroid levels of control neonates were not done. All cases included in this study received phototherapy with serial monitoring of serum bilirubin levels, till the bilirubin levels were below the range of phototherapy as defined by the American Academy of Paediatrics as per age and gestation. No cases in this study were given pharmacologic treatment or required exchange transfusion.

\section{Definition of Maternal Illness 4}

- Hypertension was defined as documented blood pressure $\geqslant 140$ / $90 \mathrm{mmHg}$ before pregnancy or before 20 weeks of gestation.

- Mothers were classified to have gestational hypertension if the blood pressure exceeded $140 \mathrm{mmHg}$ systolic or 90 $\mathrm{mmHg}$ diastolic after 20 completed weeks of gestation in a previously, normotensive women with no evidence of proteinuria.

- Pre-eclampsia was defined as the presence of proteinuria in mothers with gestational hypertension. These mothers may also have complaints of headache, epigastric pain or thrombocytopenia.

- $\quad$ Eclampsia was defined as any mother with pre-eclampsia 
who had generalized convulsions that appeared before, during or after labour, not attributed to other causes.

- The mothers who were diagnosed with diabetes before pregnancy were classified to have diabetes mellitus or overt diabetes. These mothers may have a random blood glucose level $>20 \mathrm{mg} / \mathrm{dl}$ or a fasting blood glucose level $>125 \mathrm{mg} / \mathrm{dl}$ with other signs like polyuria, polydipsia and unexplained weight loss.

- Gestational diabetes was defined as "any degree of glucose intolerance with onset or first recognition during pregnancy". This definition was used to describe gestational diabetes even if the condition persisted after pregnancy.

- PROM (Premature rupture of membranes) was defined as the rupture of membranes before the onset of labour and before 37 weeks of gestation.

- Anaemia in pregnancy was defined as a $\mathrm{Hb}$ level below $11 \mathrm{~g} / \mathrm{dl}$, according to WHO classification.

- $\quad$ The mothers were classified as having hypothyroidism if the TSH values were $>2.5 \mathrm{mIU} / \mathrm{L}$ in the first trimester or $>3 \mathrm{mIU} / \mathrm{l}$ in the second and third trimester.

- Bad obstetric history was defined as 2 or more consecutive spontaneous abortions, history of previous still birth, intrauterine foetal death or congenital anomalies in previous children. This indicates a previous unfavourable foetal outcome.

\section{Definition of Neonatal Risk Factors 4}

- The neonates were classified as IUGR, if the rate of foetal growth was lesser than the normal expected for a foetus of a particular race and gender. Clinical features of malnutrition at birth were also used to define IUGR neonates.

- Neonates who required positive pressure ventilation for more than one minute at birth, APGAR score of less than 6 at five minutes, delayed cry for more than 5 minutes or HR less than 60 / minute, where considered to have birth asphyxia.

- Preterm babies were those neonates that were delivered before 37 completed weeks of gestation.

- Polycythaemia is defined as a venous haematocrit of 65
$\%$.

- $\quad$ Sepsis is a clinical syndrome, which is characterized by systemic signs and symptoms of infection. Neonates with a positive septic screen, culture proven sepsis or clinical sepsis were considered to have sepsis.

- Breast milk jaundice is a condition that may be due to genetic predisposition, similar to Gilberts syndrome or attributed to the presence of $\beta$ glucuronidase in the breast milk. The bilirubin level increases after the first $3-5$ days and may return to normal levels if breast feeding is stopped. These infants have good weight gain, no evidence of haemolysis and normal liver function tests.

- Breastfeeding problems considered, includes a flat, inverted, cracked or sore nipple, decreased secretions, breast engorgement, mastitis, and problems with proper latch.

- Cephalohaematomas are tense swellings on the scalp, that are often present over the parietal bones as a result of subperiosteal bleeding and they do not cross the suture lines.

\section{Statistical Analysis}

All the data collected were entered in Excel 2011 and each of the variables were studied and analysed using STATA software 10.0. An ODDS ratio $>1$ was considered significant for association of risk factor with neonatal hyperbilirubinemia and a $\mathrm{P}$ value $<0.05$ was considered to be statistically significant. The risk factors which were found to be statistically significant were reanalysed through multivariate logistic regression analysis.

\section{RESULTS}

A total of 116 neonates were included in the study as cases, 3 neonates were excluded as they had congenital heart diseases. A sex and age matched $1: 1$ control $(\mathrm{N}=113)$ were included. All the babies included in our study were of Indian origin. The male to female ratio was 1.13:1. There was no significant association between gender (OR 0.74 and $P$ value 0.070 ), head circumference, length, and weight between the study groups.

\begin{tabular}{|c|c|c|c|c|c|}
\hline Groups of Risk Factors & Risk Factors & Cases $($ Total $=113) \mathrm{N}(\%)$ & Controls $($ Total $=113) \mathrm{N}(\%)$ & OR (95 \% CI) & P Value \\
\hline \multirow{7}{*}{ Maternal Illness } & GDM / DM* & $10(8.85 \%)$ & $4(3.54 \%)$ & $12.625(0.77-186.32)$ & 0.0032 \\
\hline & HTN / PIH ** & $18(15.93 \%)$ & $10(8.85 \%)$ & $1.35(0.12-7.72)$ & 0.7125 \\
\hline & Preeclampsia / eclampsia & $5(4.42 \%)$ & $3(2.65 \%)$ & $13.25(0.17-289.98)$ & 0.0136 \\
\hline & TORCH infections & $5(4.42 \%)$ & $1(0.88 \%)$ & - & 0.8289 \\
\hline & Hypothyroidism & $3(2.65 \%)$ & $1(0.88 \%)$ & - & 0.8474 \\
\hline & Anaemia & $18(15.93 \%)$ & $8(7.08 \%)$ & $3.6(0.49-20.53)$ & 0.0837 \\
\hline & PROM & $10(8.854 \%)$ & $6(5.31 \%)$ & $9.7(1.10-79.51)$ & 0.0024 \\
\hline \multirow{4}{*}{ Maternal Factors } & Bad obstetric history & $10(8.854 \%)$ & $5(4.42 \%)$ & - & 0.4760 \\
\hline & $\mathrm{ABO}$ incompatibility & $30(26.55 \%)$ & $13(11.5 \%)$ & $8.46(2.06-40.42)$ & 0.0002 \\
\hline & Rh incompatibility & $9(7.96 \%)$ & $2(1.77 \%)$ & $0.64(0.013-5.55)$ & 0.6747 \\
\hline & Breast feeding problems & $39(34.51 \%)$ & $12(10.62 \%)$ & $7.1(1.59-42.75)$ & 0.0018 \\
\hline \multirow{3}{*}{ Type of Delivery } & Normal vaginal delivery & $57(50.44 \%)$ & $23(20.35 \%)$ & $0.63(0.22-1.74)$ & 0.3326 \\
\hline & LSCS*** & $47(41.59 \%)$ & $89(78.76 \%)$ & $0.99(0.36-2.80)$ & 0.9934 \\
\hline & Instrumental delivery & $9(7.96 \%)$ & $1(0.88 \%)$ & - & 0.7676 \\
\hline Foetal Factor & IUGR & $41(36.28 \%)$ & $19(16.81 \%)$ & $14.72(3.67-83.12)$ & 0.0001 \\
\hline \multirow{6}{*}{ Neonatal Factors } & Prematurity & $46(40.71 \%)$ & $21(18.58 \%)$ & $4.91(1.58-16.82)$ & 0.0015 \\
\hline & Birth asphyxia & $16(14.16 \%)$ & $6(5.31 \%)$ & $7.23(0.85-58.22)$ & 0.0097 \\
\hline & Cephalohaematoma & $3(2.65 \%)$ & $0(0 \%)$ & - & - \\
\hline & Polycythaemia & $4(3.54 \%)$ & $0(0 \%)$ & - & - \\
\hline & Sepsis & $15(13.27 \%)$ & $0(0 \%)$ & - & - \\
\hline & Breast milk jaundice & $1(0.88 \%)$ & $0(0 \%)$ & - & - \\
\hline \multirow[t]{2}{*}{ Family History } & $\begin{array}{l}\text { History of sibling who received } \\
\text { phototherapy }\end{array}$ & $7(6.19 \%)$ & $3(2.65 \%)$ & $8.66(0.12-181.72)$ & 0.0481 \\
\hline & History of jaundice in family \# & $3(2.65 \%)$ & $1(0.88 \%)$ & 0 & 0.8683 \\
\hline & Table 1.Maternal & rs of Hyperbilirt & the Study Pol & & \\
\hline
\end{tabular}




\begin{tabular}{|cccc|}
\hline SI No. & Risk Factor & OR (95 \% CI) & P Value \\
1 & IUGR & $2.48(1.24-4.95)$ & 0.010 \\
2 & Prematurity & $2.81(1.44-5.48)$ & 0.002 \\
3 & ABO incompatibility & $2.83(1.29-6.23)$ & 0.009 \\
4 & Breast feeding problems & $3.76(1.73-8.15)$ & 0.001 \\
5 & Birth asphyxia & $2.97(0.99-8.93)$ & 0.051 \\
6 & History of sibling who received & $1.16(0.23-5.73)$ & 0.854 \\
7 & phototherapy & $1.88(0.47-7.54)$ & 0.368 \\
8 & Mothers with DM & $1.83(0.34-9.89)$ & 0.480 \\
9 & Mothers with eclampsia & Presence of PROM & 0.053 \\
\hline \multicolumn{3}{|c|}{ Table 2. Multivariate Regression Analysis } \\
\hline \multicolumn{3}{|c|}{} \\
\hline
\end{tabular}

The various risk factors considered in our study has been described in Table / Fig 1. Univariate analysis showed maternal illness like diabetes mellitus ( $\mathrm{P}$ value 0.003 ), preeclampsia ( $P$ value 0.136 ) and PROM ( $P$ value 0.0024), maternal factors like ABO incompatibility (P value 0.001 ) and breast-feeding problems (0.001), presence of IUGR (P value 0.000 ), neonatal factors like prematurity (P value 0.001 ) and birth asphyxia (P value 0.009) and family history of sibling who received phototherapy (P value 0.048 ) had a significant association with neonatal hyperbilirubinemia.

Some neonatal factors like polycythaemia, sepsis, cephalohematoma and breast milk jaundice were found only in the cases, hence their association with neonatal hyperbilirubinemia could not be commented upon.

\section{DISCUSSION}

Neonatal hyperbilirubinemia (NNH) a common condition among the neonates, may result in significant morbidity and mortality. The availability of non-invasive and effective treatment like phototherapy, has made the prompt recognition of the neonates at risk an important factor for reducing the complications associated with the condition. Through this study, an attempt was made to identify the potential modifiable risk factors associated with hyperbilirubinemia among the population included in this study. Breast feeding was found to be an important risk factor associated with hyperbilirubinemia in this study ( $P$ value 0.001 and OR 3.76), similar to studies conducted by Mostafa SA et al. ${ }^{6}$ and by Xavier R et al. ${ }^{7}$ although Kuzniewicz MW et al. ${ }^{8}$ did not find any significant association between breast feeding problems and NNH (P value 1), in their study.

ABO incompatibility 9,10 and $\mathrm{Rh}$ incompatibility ${ }^{11}$ have been studied a number of times and while some studies did not find either $\mathrm{ABO}$ or $\mathrm{Rh}$ incompatibility to be associated with a significant risk for $\mathrm{NNH},{ }^{12-16}$ this study establishes a significant association with ABO incompatibility, with $\mathrm{P}$ value 0.009 although $\mathrm{Rh}$ incompatibility was not found to have a significant association. This could be attributed to the prompt administration of Anti - D factor and better antenatal care.

Like studies by Tavakolizadeh R et al. ${ }^{17}$ and Devi DS et al. ${ }^{18}$ this study, showed a significant association of diabetes mellitus and pre-eclampsia with $\mathrm{NNH}$, through univariate analysis but multivariate regression studies did not find a significant association as described by studies by Mojtahedi SY et al. ${ }^{16}$ and Boskabadi $\mathrm{H}$ et al. ${ }^{19,20}$

Maternal anaemia and maternal hypothyroidism were not found to have a positive association with NNH in this study, in contrast to other studies. ${ }^{2,16,17}$ TORCH infections in mother did not show a significant association with the presence of $\mathrm{NNH}$, in this study.
Like other studies conducted in the US ${ }^{21}$ and India, ${ }^{2}$ this study also found PROM to have a significant association with NNH (P value 0.053 ). Although many studies ${ }^{22-24}$ stated that the type of delivery has a significant association with $\mathrm{NNH}$, this study did not find any association between the type of delivery and the presence of NNH. A study in Sweden ${ }^{25}$ showed a reduced risk for hyperbilirubinemia with planned LSCS. This could be attributed to the longer hospital stay and the proper establishment of breastfeeding among this group.

The highest prevalence of hyperbilirubinemia was found in neonates of primigravida mothers $\{47.79 \%(\mathrm{~N}=54)\}$ included in this study. This was similar to a study by Meng $\mathrm{KH}$ et al. ${ }^{3}$ although a meta-analysis by Olusanya BO et al. ${ }^{26}$ did not find any association between parity and the presence of $\mathrm{NNH}$.

Similar to other studies conducted in India, 2,18,27 IUGR was found to have a significant association with NNH (P value 0.01). Male gender has been considered as a risk factor for neonatal hyperbilirubinemia, ${ }^{28,28,29}$ but no such association was found in this study ( $P$ value 0.7). In contrast, Garosi E et al. ${ }^{30}$ showed a higher risk among female neonates for hyperbilirubinemia.

This study along with the lines of other studies, ${ }^{8,21,31}$ also found that prematurity was a risk factor for $\mathrm{NNH}$ ( $\mathrm{P}$ value 0.002 ) in contrast to studies by Singla et al. ${ }^{32}$ and Huang et al. ${ }^{15}$

Birth asphyxia in this study had a significant association with NNH (P value 0.05) like other studies conducted in India, ${ }^{2}$ Iran ${ }^{16}$ and China, 33 in contrast to a study conducted in Taiwan. ${ }^{15}$

Some studies ${ }^{33,34}$ have shown a positive association between the presence of cephalohaematoma and polycythaemia and $\mathrm{NNH}$, while others $8,16,32$ did not find a significant association.

Infections among the neonates include sepsis and UTI. UTI is difficult to diagnose among the neonates. Multiple studies 24,28,31,33-35 state that infection is a risk factor for NNH while Huang $\mathrm{M}$ - J et al. ${ }^{15}$ in their study, did not find a significant association between the two.

As only the cases included in this study had cephalohaematoma, polycythaemia and sepsis, the association could not be commented upon in this study.

G6PD tests were sent only for the cases included in this study. Only one preterm neonate had a significant result but the neonate was lost to follow up. Hence the association of the condition with the disease cannot be commented on through this study, but the prevalence of G6PD in this study population was not significant enough to recommend the routine screening of all neonates for G6PD deficiency, in the population considered for this study. A study conducted by Sinha R et al. ${ }^{36}$ found a significant association between G6PD deficiency and hyperbilirubinemia in neonates.

No neonates included in this study had hypothyroidism. Agarwal SK et al. ${ }^{37}$ in their study found breast milk jaundice to be the most common cause of neonatal hyperbilirubinemia. One neonate was diagnosed to have breast milk jaundice. The said neonate had prolonged jaundice with no other causes, hence the diagnosis was arrived at by exclusion.

Among family history, the history of a sibling with hyperbilirubinemia requiring phototherapy and positive family history for hyperbilirubinemia were considered, both of which did not have a significant association with NNH (P Value 
0.854 and 0.868 respectively) in this study although other studies $^{24,27,28,37}$ showed a significant association between a history of sibling with hyperbilirubinemia to NNH. This study considered only the predominant aetiology and not the impact of multiple aetiologies.

\section{CONCLUSIONS}

This study identifies breast feeding problems as the most common modifiable risk factor associated with neonatal hyperbilirubinemia among the population included in our study. IUGR, PROM and prematurity are risk factors that may be potentially modifiable with proper antenatal care.

Data sharing statement provided by the authors is available with the full text of this article at jemds.com.

Financial or other competing interests: All authors received grants from ICMR, during the conduct of the study.

Disclosure forms provided by the authors are available with the full text of this article at jemds.com.

\section{REFERENCES}

[1] Porter ML, Dennis BL. Hyperbilirubinemia in the term newborn. Am Fam Physician 2002;65(4):599-606.

[2] Menon S, Amanullah N. Maternal and neonatal determinants of neonatal jaundice-a case control study. J Med Sci Clin Res 2017;5(3):19659-65.

[3] Meng KH, Lee WC, Whang KT. A case-control study on the factors influencing neonatal hyperbilirubinemia. J Korean Pediatr Soc 1982;25(2):136-40.

[4] Stark AR, Bhutani VK. Neonatal Hyperbilirubinemia. In: Eichenwald EC, Hansen AR, Martin CR, et al, eds. Cloherty and stark's manual of neonatal care. $8^{\text {th }}$ edn. Philadelphia: Lipincott Williams and Wilkins 2016:335-52.

[5] Neontal jaundice: clinical guideline. 1st edn. Royal college of obstetricians and gynaecologists. London, England: 27 Sussex Place, Regent's Park 2010: p. 517. https://www.nice.org.uk/guidance/cg98/evidence/fullguideline-245411821

[6] Mostafa SA, Aljeesh Y, Hamad KA, et al. Risk factors of hyperbilirubinemia among admitted neonates in the gaza strip: case control study. Public Health Res 2017;7(2):3945.

[7] Xavier R, Manoj VC, Cherian VJ. Breastfeeding jaundice: how big is the problem? Int J Contemp Pediatr 2016;3(2):498-503.

[8] Kuzniewicz MW, Escobar GJ, Wi S, et al. Risk factors for severe hyperbilirubinemia among infants with borderline bilirubin levels: a nested case-control study. J Pediatr 2008;153(2):234-40.

[9] Kalakheti BK, Singh R, Bhatta NK, et al. Risk of neonatal hyperbilirubinemia in babies born to " $O$ " positive mothers: a prospective cohort study. Kathmandu Univ Med J (KUMJ) 2009;7(25):11-5.

[10] Patel AS, Desai DA, Patel AR. Association of ABO and Rh incompatibility with neonatal hyperbilirubinaemia. Int J Reprod Contracept Obstet Gynecol 2017;6(4):1368-75.

[11] Bhutani VK, Zipursky A, Blencowe H, et al. Neonatal hyperbilirubinemia and rhesus disease of the newborn: incidence and impairment estimates for 2010 at regional and global levels. Pediatr Res 2013;74(S1):86-100.

[12] Khurana R, Batra P, Faridi M, et al. Revisiting ABO incompatibility as a risk factor for significant neonatal hyperbilirubinemia. Trop Doct 2019;49(3):201-4.

[13] Sgro M, Campbell D, Shah V. Incidence and causes of severe neonatal hyperbilirubinemia in Canada. CMAJ 2006;175(6):587-90.

[14] Akgül S, Korkmaz A, Yiğit S, et al. Neonatal hyperbilirubinemia due to ABO incompatibility: does blood group matter? Turk J Pediatr 2013;55(5):506-9.

[15] Huang MJ, Kua KE, Teng HC, et al. Risk factors for severe hyperbilirubinemia in neonates. Pediatr Res 2004;56(5):682-9.

[16] Mojtahedi SY, Izadi A, Seirafi G, et al. Risk factors associated with neonatal jaundice: a cross-sectional study from Iran. Open Access Maced J Med Sci 2018;6(8):138793.

[17] Tavakolizadeh R, Izadi A, Seirafi G, et al. Maternal risk factors for neonatal jaundice: a hospital-based crosssectional study in Tehran. Eur J Transl Myol 2018;28(3):7618.

[18] Devi DS, Vijaykumar B. Risk factors for neonatal hyperbilirubinemia: a case control study. Int J Reprod Contracept Obstet Gynecol 2016;6(1):198-202.

[19] Boskabadi H, Rakhshanizadeh F, Zakerihamidi M. Evaluation of maternal risk factors in neonatal hyperbilirubinemia. Arch Iran Med 2020;23(2):128-40.

[20] Boskabadi H, Khakshoor A, Khorashadizadeh F, et al. Prenatal complications causing neonatal jaundicein Ghaem hospital, Mashhad-Iran. J North Khorasan Univ Med Sci 2011;3(2):7-12.

[21] Geiger AM, Petitti DB, Yao JFF. Rehospitalisation for neonatal jaundice: risk factors and outcomes. Paediatr Perinat Epidemiol 2001;15(4):352-8.

[22] Gupta A, Gupta P, Ali SSL, et al. Effect of mode of delivery: normal, induced and caesarean section on neonatal serum bilirubin. Indian J Clin Anat Physiol 2016;3(3):266-9.

[23] Brits H, Adendorff J, Huisamen D, et al. The prevalence of neonatal jaundice and risk factors in healthy term neonates at National District Hospital in Bloemfontein. Afr J Prim Health Care Fam Med 2018;10(1):e1-6.

[24] Najib KS, Saki F, Hemmati F, et al. Incidence, risk factors and causes of severe neonatal hyperbilirubinemia in the South of iran (fars province). Iran Red Crescent Med J 2013;15(3):260-3.

[25] Norman M, Åberg K, Holmsten K, et al. Predicting nonhemolytic neonatal hyperbilirubinemia. Pediatrics 2015;136(6):1087-94.

[26] Olusanya BO, Osibanjo FB, Slusher TM. Risk factors for severe neonatal hyperbilirubinemia in low and middleincome countries: a systematic review and meta-analysis. PLoS One 2015;10(2):e0117229.

[27] Singla DA, Sharma S, Sharma M, et al. Evaluation of risk factors for exchange range hyperbilirubinemia and neurotoxicity in neonates from Hilly Terrain of India. Int J Appl Basic Med Res 2017;7(4):228-32.

[28] Bulbul A, Cayonu N, Sanli ME, et al. Evaluation of risk factors for development of severe hyperbilirubinemia in term and near term infants. Pak J Med Sci 2014;30(5):1113-8. 
[29] Scrafford CG, Mullany LC, Katz J, et al. Incidence of and risk factors for neonatal jaundice among newborns in southern Nepal. Trop Med Int Health 2013;18(11):131728.

[30] Garosi E, Mohammadi F, Ranjkesh F. The relationship between neonatal jaundice and maternal and neonatal factors. Iranian Journal of Neonatology IJN 2016;7(1):3740.

[31] Zabeen B, Nahar J, Nabi N, et al. Risk factors and outcome of neonatal jaundice in a tertiary hospital. Ibrahim Medical College Journal 2010;4(2):70-3.

[32] Singla DA, Sharma S, Sharma M, et al. Evaluation of risk factors for exchange range hyperbilirubinemia and neurotoxicity in neonates from Hilly Terrain of India. Int J Appl Basic Med Res 2017;7(4):228-32.

[33] Han J, Liu X, Zhang F. Effect of the early intervention on neonate with hyperbilirubinemia and perinatal factors. Biomedical Research 2017;28(1).
[34] Shetty A, Kumar BS. A study of neonatal hyperbilirubinemia in a tertiary care hospital. Int J Med Sci Public Health 2014;3(10):1289-93.

[35] Maamouri G, Khatami F, Mohammadzadeh A, et al. Hyperbilirubinemia and neonatal infection. International Journal of Pediatrics 2013;1(1):5-12.

[36] Sinha R, Sachendra B, Syed VS, et al. To study the prevalence of glucose 6 phosphate dehydrogenase (G6PD) deficiency in neonates with neonatal hyperbilirubinemia and to compare the course of the neonatal jaundice in deficient versus non deficient neonates. J Clin Neonatol 2017;6(2):71-4.

[37] Agrawal SK, Kumar P, Rathi R, et al. UGT1A1 gene polymorphisms in North Indian neonates presenting with unconjugated hyperbilirubinemia. Pediatr Res 2009;65(6):675-80. 